\title{
Damage profiles of ultrashallow B implants in Si and the Kinchin-Pease relationship
}

\author{
J. A. van den Berg, ${ }^{\text {a) }}$ G. Carter, D. G. Armour, and M. Werner \\ Joule Physics Laboratory, Institute of Materials Research, University of Salford, Salford M5 4WT, \\ United Kingdom \\ R. D. Goldberg and E. J. H. Collart \\ Ion Implant Division, Applied Materials, Foundry Lane, Horsham RH13 5PX, United Kingdom \\ P. Bailey and T. C. Q. Noakes \\ CCLRC Daresbury Laboratory, Daresbury Cheshire, WA4 4AD, United Kingdom
}

(Received 9 April 2004; accepted 4 August 2004)

\begin{abstract}
Damage distributions resulting from $0.1-2 \mathrm{keV} \mathrm{B}^{+}$implantation at room temperature into $\mathrm{Si}(100)$ to doses ranging from $1 \times 10^{14}$ to $2 \times 10^{16} \mathrm{~cm}^{-2}$ have been determined using high-depth-resolution medium-energy-ion scattering in the double alignment mode. For all $\mathrm{B}^{+}$doses and energies investigated a 3-4 nm deep, near-surface damage peak was observed while for energies at and above $1 \mathrm{keV}$, a second damage peak developed beyond the mean projected $\mathrm{B}^{+}$ion range of $5.3 \mathrm{~nm}$. This dual damage peak structure is due to dynamic annealing processes. For the near-surface peak it is observed that, at the lowest implant energies and doses used, for which recombination processes are suppressed due to the proximity of the surface capturing interstitials, the value of the damage production yield for low-mass $\mathrm{B}^{+}$ions is equal or greater than the modified Kinchin-Pease model predictions [G. H. Kinchin and R. S. Pease, Rep. Prog. Phys. 18, 1 (1955); G. H. Kinchin and R. S. Pease, J. Nucl. Energy 1, 200 (1955); P. Sigmund, Appl. Phys. Lett. 14, 114 (1969)]. (C) 2004 American Institute of Physics. [DOI: 10.1063/1.1801671]
\end{abstract}

The Kinchin-Pease ${ }^{1,2}$ relationship, first developed to describe interstitial-vacancy pair production in nuclear reactors, has been widely used as a theoretical comparator for such production yields in ion implanted solids. A more realistic description of interatomic forces ${ }^{3}$ only changes the predicted yields by a few percent but not the fundamental form of the relationship

$$
\nu(E)=\frac{k f(E)}{E_{d}},
$$

where $\nu(E)$ is the production yield, stable against recombination, for ions in which the energy deposited in elastic collision processes is $f(E), E_{d}$ is the energy required to permanently displace an atom and $k$ is a constant $(=0.42) .^{3}$

This relationship is valid in the linear cascade regime where collisions are considered to occur only between pairs of moving and stationary atoms. If this is not obeyed then energy spike conditions are considered to prevail ${ }^{4}$ and defect pair production yields can considerably exceed linear cascade predictions. This situation usually occurs for heavy ions and high atomic weight targets.

However light ion irradiation of low atomic weight materials such as $\mathrm{Si}$, where linear cascade conditions should operate, usually leads to observed production yields well below linear cascade predictions ${ }^{5-7}$ although for heavier ions values in excess of these have been measured ${ }^{5-7}$ consistent with expected spike behavior. Such observations have been made with ions of energies in the tens of $\mathrm{keV}$ range and above and the former behavior has been ascribed to thermal recombination, or dynamic annealing, of migrating defects. In the present study of very low energy $B$ ion implantation of

\footnotetext{
${ }^{a)}$ Electronic mail: j.a.vandenberg@salford.ac.uk
}

$\mathrm{Si}$, it is demonstrated that if this thermal recombination can be suppressed then pair production yields close to linear cascade predictions can be observed.

$\mathrm{B}^{+}$ions were implanted into $\mathrm{Cz}$ grown $\mathrm{Si}(100)$ samples (of resistivity 10-20 $\Omega \mathrm{cm}$ ) through the native oxide, at energies between 0.1 and $2 \mathrm{keV}$ to a maximum dose of 2 $\times 10^{16} \mathrm{~cm}^{-2}$ using a dose rate of $10 \mu \mathrm{A} \mathrm{cm} \mathrm{cm}^{-2} \mathrm{~s}^{-1}$. The implants were carried out using the Salford ultralow energy implanter. ${ }^{8}$

MEIS analysis was performed at CCLRC Daresbury

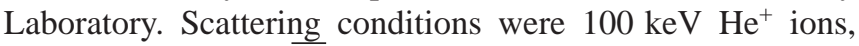
incident along the [111] channeling direction and detected along the [331] blocking direction. The effective depth resolution was $0.8 \mathrm{~nm}$ as determined from the Si edge in the random direction. Damage depth distributions (in terms of the number of displaced $\mathrm{Si}$ atoms $\mathrm{cm}^{-2}$ per unit depth) are determined from the energy spectra using a standard calibration procedure in which the ion yields are referenced to the random level obtained for amorphised $\mathrm{Si}$ and the energy scale is converted into a depth scale by applying the surface approximation $^{9,10}$ in conjunction with established inelastic energy loss data. ${ }^{11}$

Figure 1(a) shows the dependence of the MEIS energy spectra on the implant energy, from $100 \mathrm{eV}$ to $1 \mathrm{keV}$, for a $\mathrm{B}^{+}$dose of $5 \times 10^{14} \mathrm{~cm}^{-2}$ at room temperature. ${ }^{12}$ The spectrum for the native oxide covered, virgin $\mathrm{Si}$ is shown for comparison. Three peaks, indicated by $\mathrm{Si}, \mathrm{O}$, and $\mathrm{C}$ and resulting from scattering off near-surface $\mathrm{Si}, \mathrm{O}$, and $\mathrm{C}$ atoms, respectively, are clearly visible. The $\mathrm{Si}$ surface peak (edge at $92 \mathrm{keV}$ ) for the virgin sample is due to the $\mathrm{Si}$ atoms present in the native oxide layer and $\mathrm{Si}$ atoms displaced at the oxide/Si interface. ${ }^{13}$ After subtraction of the contribution of the $\mathrm{Si}$ atoms in the oxide it is found that the surface peak has 


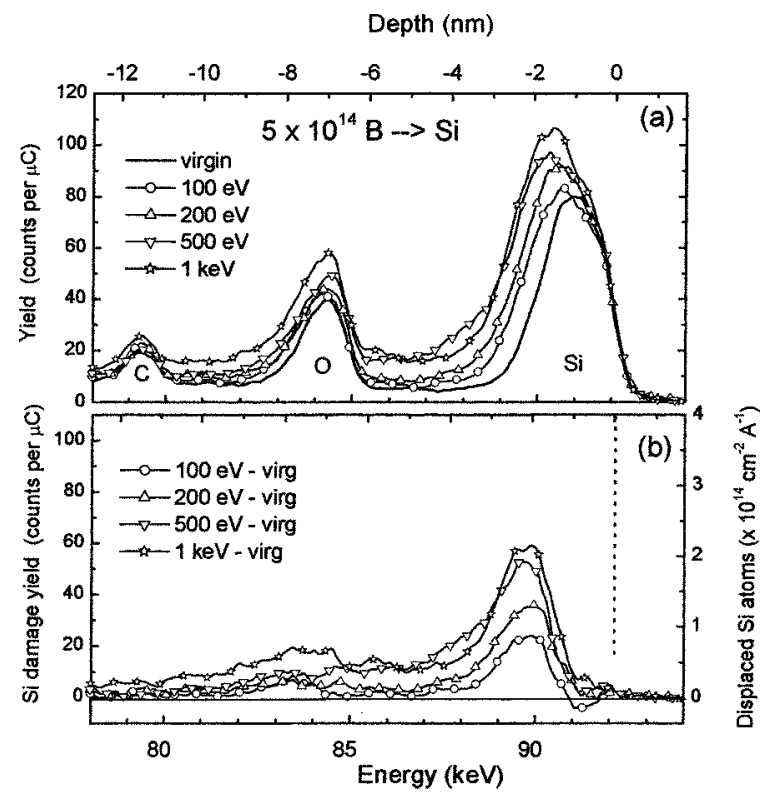

FIG. 1. MEIS spectra of (a) $\mathrm{Si}(100)$ before and after implantation with $\mathrm{B}^{+}$ ions to a dose of $5 \times 10^{-14} \mathrm{~cm}^{-2}$ at energies from $100 \mathrm{eV}$ to $1 \mathrm{keV}$, and (b) after subtraction of the virgin $\mathrm{Si}$ spectrum showing damage depth profiles.

a contribution of a maximum of $4.5 \times 10^{15}$ atoms $\mathrm{cm}^{-2} \mathrm{Si}$ atoms that are located in a disordered or relaxed layer just below the Si oxide interface. ${ }^{12}$ The number of additional $\mathrm{Si}$ atoms displaced by the low energy implantation must be seen against this base number.

The growth of the Si surface peak with increasing implant energy, as shown in Fig. 1(a) is caused by extra, deeper lying displaced $\mathrm{Si}$ atoms that cause an additional backscattering yield. The calculated depth scale for these displaced $\mathrm{Si}$ atoms is indicated at the top of the spectrum. As the $\mathrm{B}^{+}$ implant energy increases, the damage region extends to greater depth starting at the oxide interface. From a FWHM of $1.7 \mathrm{~nm}$ for the virgin $\mathrm{Si}$, the surface peak width increases to $2.5 \mathrm{~nm}$ for both $500 \mathrm{eV}$ and $1 \mathrm{keV} \mathrm{B}{ }^{+}$irradiation. At $2 \mathrm{keV}$ no further increase in width is observed. In order to estimate the number of the displaced $\mathrm{Si}$ atoms as a function of depth due to the $\mathrm{B}^{+}$implant only, the virgin Si spectrum was subtracted from the other spectra. These difference spectra are shown in Fig. 1(b), where the right-hand side axis gives the areal density of displaced $\mathrm{Si}$ atoms per unit depth (A). The overall dependence of the Si damage depth profiles on the $\mathrm{B}^{+}$ion energy is remarkably weak. Note that for $1 \mathrm{keV} \mathrm{B}{ }^{+}$ions after a dose of $5 \times 10^{14} \mathrm{~B}^{+} \mathrm{cm}^{-2}$, a second, deeper damage peak is detected. It has a maximum at a depth of $7.5 \mathrm{~nm}$ which is well beyond $R_{p} \approx 5.3 \mathrm{~nm}$, calculated by TRIM $^{14}$ for $1 \mathrm{keV} \mathrm{B}^{+}$ions. Previous MEIS studies of $1 \mathrm{keV} \mathrm{B}$ implants carried out at temperatures of -120 and $300^{\circ} \mathrm{C}^{12}$ have clearly demonstrated that this double damage peak structure is caused by dynamic annealing processes in the intermediate region. Si recoil and vacancy production for $1 \mathrm{keV} \mathrm{B}$ implants are calculated to have their highest yields at 3 and $3.5 \mathrm{~nm}$ depth, respectively. This coincides with the region that shows the highest degree of dynamic annealing at this energy. The small peaks at a depth of $8 \mathrm{~nm}$ for the lower implant energy spectra in Fig. 1(b), are ascribed to a small post-implant growth in the oxide layer and/or recoil implanted $\mathrm{O}$ atoms from the oxide.

Figure 2(a) shows pronounced buildup of surface damage for an implant energy of $200 \mathrm{eV}$ for doses from 1
Downloaded 22 Mar 2005 to 146.87 .126 .245 . Redistribution subje

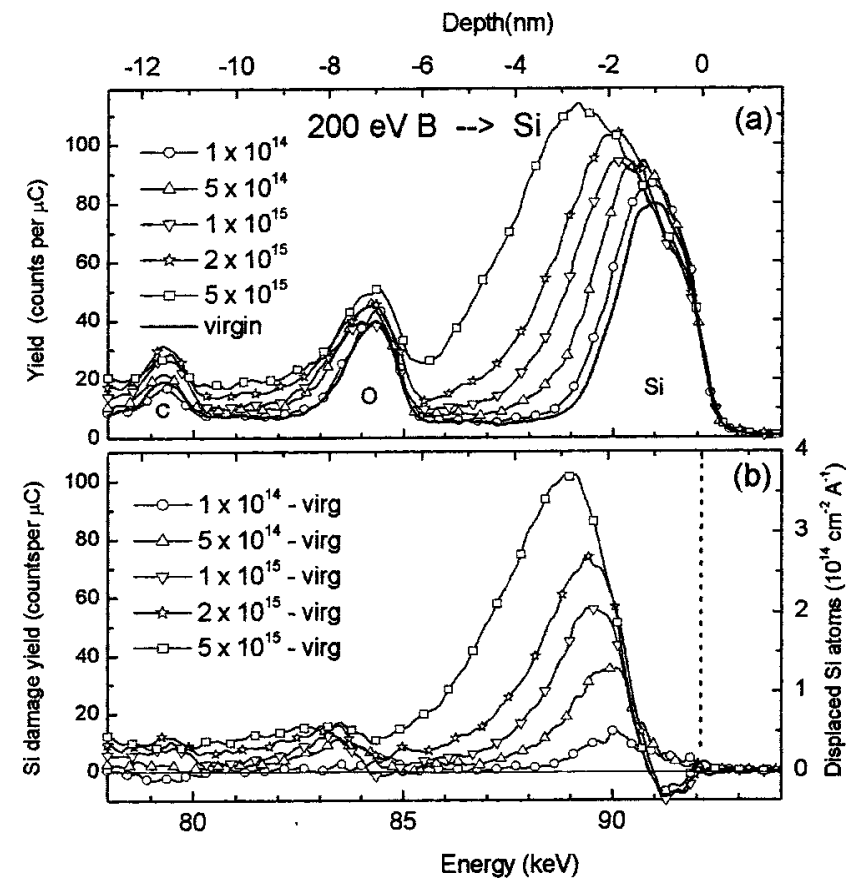

FIG. 2. MEIS spectra of (a) $\mathrm{Si}(100)$ before and after implantation with $200 \mathrm{eV} \mathrm{B}^{+}$ions to doses between $1 \times 10^{-14}$ to $5 \times 10^{-15} \mathrm{~cm}^{-2}$ and (b) after subtraction of the virgin $\mathrm{Si}$ spectrum showing damage depth profiles.

$\times 10^{14}$ to $5 \times 10^{15} \mathrm{~B}^{+} \mathrm{cm}^{-2}$. As in Fig. 1 the virgin Si spectrum was subtracted to obtain the damage depth profiles, produced by the $\mathrm{B}^{+}$implant only and these are shown in Fig. 2(b). MEIS is capable of detecting Si displacements due to $\mathrm{B}^{+}$implants to doses as low as $1 \times 10^{14} \mathrm{~B}^{+}$ions $\mathrm{cm}^{-2}$ at $200 \mathrm{eV}$. Under these conditions there will be little overlap between collision cascades, and the effective number of $\mathrm{Si}$ displacements per $\mathrm{B}^{+}$ion is calculated to be $\sim 8.3$. Note that this is an underestimate since any implant damage produced in the oxide/damage layer is not detected. The value is in fair agreement with that of 6.5 obtained from Eq. (1), taking $E_{d}$ as $13 \mathrm{eV}$ and setting $f(E)=E$. The latter neglects inelastic energy losses that may amount to $30 \%$ and hence 6.5 is an upper limit. Figure 3(a) shows the dependence of the ratio of the experimentally determined number of displaced $\mathrm{Si}$ atoms per incoming $\mathrm{B}^{+}$ion (production yield) over the Kinchin Pease predicted value, $\nu(E)=6.5$ of Eq. (1), as a function of increasing dose for the $200 \mathrm{eV} \mathrm{B}$ implant. It is clear that the production yield decreases continuously and reduces to 2.2

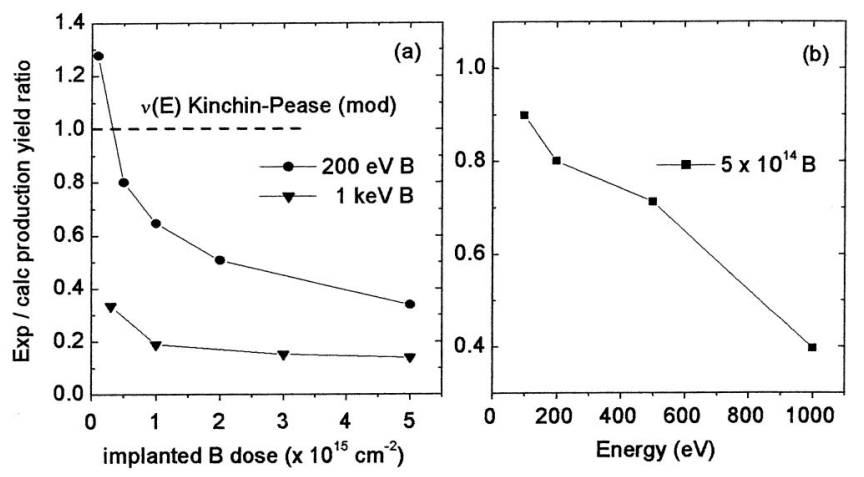

FIG. 3. (a) Experimental damage production yields in $\mathrm{Si}$ for $200 \mathrm{eV}$ and $1 \mathrm{keV} \mathrm{B}^{+}$ions over the modified Kinchin-Pease damage production yield ratio given by Eq. (1); (b) idem as function of energy for a $\mathrm{B}^{+}$ion dose of $5 \times 10^{-14} \mathrm{~cm}^{-2}$. 
for the higher $\mathrm{B}^{+}$dose of $5 \times 10^{15} \mathrm{~cm}^{-2}$. The latter value compares well to the $\nu(E)=3$ for $250 \mathrm{eV} \mathrm{B}^{+}$implanted into $\mathrm{Si}$, calculated from high depth resolution RBS measurements. ${ }^{15}$ This reduction in $\nu(E)$ for higher doses is expected since the damage will saturate as fewer crystalline regions remain.

From the data shown in Fig. 1(b) the value of $\nu(E)$ for fixed ion dose as a function of increasing ion energy is obtained and this is again shown in Fig. 3(b) relative to the theoretically predicted value given by Eq. (1). As the energy increases, the relative value becomes progressively smaller due to the increasingly effective Frenkel defect recombination probability as the damaged region moves out of the trapping range of the surface/oxide interface. This is also seen in the relative production yield ratios for $1 \mathrm{keV} \mathrm{B}^{+}$as a function of dose, obtained from the data in Ref. 12 and included in Fig. 3(a) for comparison. The ratio is well below 1 and the effect of increasing dose at $1 \mathrm{keV}$ is very weak.

MEIS shows that all the B implants considered are characterized by the growth of a highly damaged/amorphous layer up to a thickness of up to $\approx 4 \mathrm{~nm}$. This has been confirmed by XTEM. ${ }^{16}$ As reported previously, ${ }^{12}$ it appears that point defects ( $\mathrm{Si}$ interstitials) produced along the range of the implant, which are mobile at room temperature, migrate to and are trapped at the $\mathrm{Si}$ /oxide interface sink, a process first proposed in Ref. 17. The development of a shallow, highly damaged/amorphous layer for these low energy $\mathrm{B}^{+}$implants has been confirmed by spectroscopic ellipsometry (SE) measurements ${ }^{18}$ and high resolution RBS/C. ${ }^{15}$

In conclusion MEIS has provided quantitative information on the behavior of the Si lattice disorder as a function of depth with subnanometer resolution. In the energy range considered, $\mathrm{B}^{+}$ion bombardment at $\mathrm{RT}$ resulted in the formation of a narrow surface damage layer to a depth of up to $\approx 4 \mathrm{~nm}$, the growth of which has a strong dependence on dose, but a weak dependence on energy. For energies at and above $1 \mathrm{keV}$ and doses above $5 \times 10^{14} \mathrm{~cm}^{-2}$ a second, deeper damaged layer was resolved, the maximum of which lay below the mean projected range of the implanted ions. MEIS studies have shown that this post-implant damage structure is the result of dynamic annealing processes during $\mathrm{B}^{+}$implantation, and that these processes are particularly effective in the region in which Frenkel defects have their maximum production yields.

Significantly, MEIS studies have demonstrated that, providing defect recombination processes can be inhibited, values of the defect production yield close to or exceeding the predictions of the Kinchin-Pease model can be obtained. In the present study it is argued that this can be achieved, for B at RT, by the use of very low energy ions so that defects migrate to and are trapped at the $\mathrm{Si}$ /oxide interface with minimized probability of recombination. At low doses and mean defect density levels (say $0.5 \%$ ), this defect escape is complete and the measured defect production yields compare well with the predictions of linear cascade theory. As dose and defect densities increase, recombination also increases, so that even at energies as low as $200 \mathrm{eV}$ where the interface sink is close to the depth of defect creation, the measured defect creation yield decreases due to increased recombination. With increasing ion energy the depth of defect creation moves away from the interface sink so that recombination rather than escape to the sink dominates and measured relative production yields decrease. This behavior explains why earlier studies using considerably higher energy ions have generally provided defect production yields much less than theory predicts. It is suggested that even with higher energy ions similar agreement with theoretical predictions could be obtained for implantation at sufficiently low temperatures where defect migration and annihilation would be prevented.

${ }^{1}$ G. H. Kinchin and R. S. Pease, Rep. Prog. Phys. 18, 1 (1955).

${ }^{2}$ G. H. Kinchin and R. S. Pease, J. Nucl. Energy 1, 200 (1955).

${ }^{3}$ P. Sigmund, Appl. Phys. Lett. 14, 114 (1969).

${ }^{4}$ P. Sigmund, Appl. Phys. Lett. 25, 169 (1974).

${ }^{5}$ J. A. Davies, J. Den Hartog, L. Eriksson, and J. W. Mayer, Can. J. Phys. 45, 4053 (1967)

${ }^{6}$ F. H. Eisen and B. Welch, Proceedings of the European Conference on Ion Implantation (Peregrinus, London, 1970), p. 227.

${ }^{7}$ D. A. Thompson, A. Golanski, H. K. Haugen, D. V. Stevanovic, G. Carter, and C. E. Christodoulides, Radiat. Eff. 52, 69 (1980).

${ }^{8}$ R. D. Goldberg, D. G. Armour, J. A. van den Berg, N. Knorr, H. Ohno, S. Whelan, S. Zhang, C. E. A. Cook, and M. A. Foad, Rev. Sci. Instrum. 71, $1032(2000)$

${ }^{9}$ J. F. van der Veen, Surf. Sci. Rep. 5, 199 (1985).

${ }^{10}$ W. K. Chu, J. W. Mayer, and M. Nicolet, Backscattering Spectrometry (Academic, New York, 1978).

${ }^{11}$ J. F. Ziegler, J. P. Biersack, and U. Littmark, The Stopping and Range of Ions in Solids (Pergamon, New York, 1985).

${ }^{12}$ J. A. van den Berg, S. Zhang, D. G. Armour, S. Whelan, R. D. Goldberg, E. J. H. Collart, P. Bailey, and T. C. Q. Noakes, Nucl. Instrum. Methods Phys. Res. B 183, 154 (2001).

${ }^{13}$ A. H. Al-Bayati, K. Ormann-Rossiter, J. A. van den Berg, and D. G. Armour, Surf. Sci. 241, 91 (1991).

${ }^{14}$ J. P. Biersack and L. G. Haggmark, Nucl. Instrum. Methods 174, 257 (1980).

${ }^{15}$ E. H. J. Collart, M. Heijdra, K. Weemers, Y. Tamminga, J. G. M. van Berkum, and M. A. Verheijen, Proceeding of the 12th International Conference on Ion Implantation Technology (IIT-98), Kyoto (IEEE, Piscataway, NJ, 1998).

${ }^{16}$ T-S. Wang, A. G. Cullis, E. H. J. Collart, A. J. Murrell, M. A. Foad, and J. A. van den Berg, Proc Microsc. Mater. Conf. (Oxford, 1999), Inst. Phys. Conf. Ser. 164, 459 (1999).

${ }^{17}$ I. A. Abroyan, A. I. Titov, and A. V. Khlebalkin, Sov. Phys. Semicond. 11, 712 (1977).

${ }^{18}$ W. Fukarek, W. Möller, N. Hatzopoulos, D. G. Armour, and J. A. van den Berg, Nucl. Instrum. Methods Phys. Res. B 127/128, 879 (1997). 